\title{
1 A quantitative model for metabolic intervention using gut microbes
}

2 Zachary JS Mays ${ }^{1}$ and Nikhil U Nair ${ }^{1 *}$

$3{ }^{1}$ Department of Chemical \& Biological Engineering, Tufts University, Medford, MA 02155

4 * nikhil.nair@tufts.edu; @nair lab

\section{Abstract}

6 As medicine shifts toward precision-based and personalized therapeutics, utilizing more complex biomolecules to

7 treat increasingly difficult and rare conditions, microorganisms provide an avenue for realizing the production and processing necessary for novel drug pipelines. More so, probiotic microbes can be co-opted to deliver therapeutics by oral administration as living drugs, able to survive and safely transit the digestive tract. As living therapeutics are

10 in their nascency, traditional pharmacokinetic-pharmacodynamic (PK-PD) models for evaluating drug candidates

11 are not appropriate for this novel platform. Using a living therapeutic in late-stage clinical development for

12 phenylketonuria (PKU) as a case study, we adapt traditional oral drug delivery models to properly evaluate and

13 inform the engineering of living therapeutics. We develop the adapted for living therapeutics compartmental

14 absorption and transit (ALT-CAT) model to provide metrics for drug efficacy across nine age groups of PKU patients

15 and evaluate model parameters that are influenced by patient physiology, microbe selection and therapeutic

16 production, and dosing formulations.

\section{Importance}

18 This work describes a kinetic model to study the behavior of orally delivered living therapeutics. Such therapeutics

19 are becoming increasingly relevant and are an exciting mode of drug delivery that stems from the growing interest

20 through the convergence of advances in synthetic biology of probiotics and gut microbes as well as microbiome

21 science. In particular, this work describes the development of a mathematical framework (pharmacokinetic-

22 pharmacodynamic, PK-PD) called ALT-CAT to model the behavior of orally delivered engineered bacteria that act as

23 living therapeutics by adapting similar methods that have been developed and widely-used for small molecular drug

24 delivery and absorption. 


\section{Introduction}

26 The most common and practical route of drug delivery is oral ingestion, pairing patient convenience and high 27 compliance with ease of administration and stability. While a simple initial assessment of a drug's biochemical feasibility for oral delivery can be predicted using the biopharmaceutical classification system (BCS) (1) or rule of five (Ro5) (2), these evaluations do not inform the further complexities of selecting lead candidates, developing a dosage or release strategy, effective bioavailability, and pharmacokinetics. Accordingly, a range of models - in vitro (3) and in vivo (4), static (5) and dynamic $(6,7)$, molecular (8) and system environment (9) - are used extensively in drug development to evaluate and hone desired features.

An economically appealing alternative, trading human capital and consumables for computational resources (time and power), is the modeling of drug absorption in the gastrointestinal tract (GIT). In silico models have been developed for both molecular interactions (10), such as receptor binding or transport, and physiology-based pharmacokinetics (PBPK) (11), such as compartment disposition or clearance. Several commercial software packages based on these models (12-14) incorporate drug physiochemical properties (solubility, degradation, permeability, molecular size, aggregation, charge), formulation properties (dosage, drug release profiles, absorption enhancers, matrix polymorphism), and Gl physiological properties (gastric emptying, intestinal $\mathrm{pH}$, motility, luminal content,

41 transporters, metabolism, epithelial sequestration, disease state). Most notably, GastroPlus ${ }^{\mathrm{TM}}$ (Simulations Plus,

42 Lancaster, CA) was conceived from the advanced compartmental absorption and transit (ACAT) model (15), separating the small intestine $(\mathrm{SI})$ into a series compartments and solving the differential equations surrounding drug mass transfer.

While in silico oral drug absorption models have proven invaluable to the drug development pipeline, an emerging

47 class of therapeutic candidates are not addressed with current methodologies. Living therapeutics (also termed 
49 have been programmed to produce drugs, potentially with autonomous contextual awareness (16-18). These

50 microbes are chosen and designed to be compatible with the human gut microbiota, acting not only as drug

51 producers but as delivery vehicles that can survive and traverse the harsh environment of the gut. The living

52 therapeutics platform offers several potential advantages including a constant or timed drug release, real-time dose

53 changes, spatial targeting of delivery, sub-clinical detectability, and the production of large or complex

54 biomacromolecules normally incompatible with oral delivery (19). The latter is the basis of an enzyme-substitution

55 therapy (EST) for phenylketonuria (PKU) in probiotic Escherichia coli Nissle 1917 (EcN) that is currently in Phase 1/2a

56 clinical trials (SYNB1618, Synlogic Inc; ClinicalTrials.gov identifier NCT03516487) (20). Here, the enzyme

57 phenylalanine ammonia-lyase (PAL) expressed in EcN converts excess toxic phenylalanine (phe) to the non-

58 metabolite trans-cinnamic acid $(t C A)$ and provides therapeutic benefit.

It is clear where the limitations of current oral drug absorption models arise when considering living therapeutics.

61 The "drug" being delivered is actually a microbe that produces a catalytically active enzyme, can adhere to the gut

62 mucosal layer, can replicate, and change PAL expression levels. Furthermore, if a PKU patient consumes protein

63 containing phe, absorption of phe is counterproductive, while degradation (i.e. PAL conversion of phe to tCA) is the

64 desired outcome. Thus, this model must account for competition between absorption of a toxin (phe) and catalytic

65 depletion by an enzyme. Finally, just as first-pass hepatic elimination affects a drug bioavailability profile,

66 enterorecirculation of amino acids can affect concentrations of phe in the gut lumen and boost the efficacy of PAL

67 independent of meal phe (21).

69 Using a PAL-based treatment of PKU as the case study for living therapeutic treatments $(20,22-25)$, this work

70 presents the a adapted for living therapeutics compartmental absorption and transit (ALT-CAT) in silico model, which

71 incorporates the physiology of the Gl tract, different bacterial chassis, and different expression levels of PAL into the

72 traditional compartmental model (9). The CAT model was adapted to populate the SI with a microbial population 
73 and combined with the stochastic gastric emptying ( $\mathrm{sGE}$ ) model to simulate a non-linear emptying of the stomach.

74 A fraction of the microbial population was designated to be a living therapeutic expressing PAL to degrade phe. A therapeutic factor (TF) was created to assess model parameters such as bacteria population, enzyme activity, and phe transport. Target concentrations of phe in the blood were used as output for therapeutic efficacy. This work presents a refreshed toolset for the evaluation and comparison of living therapeutic constructs and their parts therein, serving as a benchmark for designing orally administered drug formulations.

\section{Model construction}

81 The original CAT model determined that a cumulative time frequency distribution of 400 human $\mathrm{SI}$ transit times is

82 best represented by seven equal transit compartments (Equation 1). Drug absorption can then be derived within

83 each compartment, relating drug bioavailability to its effective permeability coefficient ( $\left.P_{\text {eff }}\right)$ (Equation 2). Drug

84 dissolution, pH-dependent solubility, first-pass hepatic metabolism, degradation, and other region-dependent

85 factors were added later in the ACAT model, the foundation for GastroPlus ${ }^{\mathrm{TM}}$ software. With these equations, $M_{n}$ is

86 the amount of drug in the $\mathrm{n}^{\text {th }}$ compartment $(\mathrm{mg}) ; k_{T}$ is the transit rate constant through the compartment $\left(\mathrm{min}^{-1}\right)$;

$87 T_{S /}$ is the average transit time through the small intestine $(\mathrm{min}) ; r$ is the luminal radius $(\mathrm{cm}) ;$ and $F_{a}$ is the fraction of

88 dose absorbed (9). In our modification, we model the dynamics of toxin (phe in case of PKU) absorption using these

89 equations.

$$
\begin{gathered}
\frac{d M_{n}}{d t}=k_{T} M_{n-1}-k_{T} M_{n}, \quad n=1,2, \ldots, 7 \\
F_{a}=1-\left(1+\frac{2 P_{e f f}\left\langle T_{S I}\right\rangle}{7 r}\right)^{-7}
\end{gathered}
$$

Equation 1

Equation 2

90 While gastric and colonic drug absorption were included in the CAT model as well, the stomach is modeled by linear

91 emptying, and flow is estimated by first-order ordinary differential equations as a plug-flow reactor (26).

92 Physiologically, gastric emptying is a more complex process involving churning contractions, both peristalsis and

93 retroperistalsis, controlled opening of the pyloric sphincter, solid versus liquid digesta, and hormonal feedback to 
94 macronutrient composition. These coordinated movements are observed as sporadic and irregular bolus injections

95 over approximately three to four hours. Several continuous smooth equations have been employed to loosely

96 generalize observed data (27), but more recently, to better account for this, a stochastic gastric emptying (sGE)

97 model was developed by adapting the power exponential form of a standard Wiener process (Equation 3). This was

98 then used to track a decreasing monotonic jump process (Equation 4). Here, $\alpha$ and $\beta$ are empirical parameters found

99 to give $90 \%$ confidence intervals that describe the data in Locatelli, et al. (2009) (28).

$$
\begin{array}{cc}
X(t)=e^{-\alpha|W(t)|^{\beta}} & \text { Equation } 3 \\
S(t)=\min _{0<s<t} X(s) & \text { Equation } 4 \\
\frac{d M_{s}}{d t}=f(S):\left[\tau_{i-1}, \tau_{i}\right] \rightarrow \mathbb{R}, \quad i=1,2, \ldots, T_{s} & \text { Equation } 5
\end{array}
$$

100 A crucial difference between modeling traditional oral drug delivery and an EST is that the former is designed to

101 maximize absorption (and therefore bioavailability) of a drug, while the latter is meant to prevent absorption of a 102 toxic metabolite. With highly permeable or quickly transported small molecules, such as phe in the case of PKU, the 103 rate limiting step of absorption is gastric emptying. As such, modeling gastric emptying more accurately with the 104 sGE model and combining this with the ACAT model was the framework for constructing the ALT-CAT model for 105 PKU treatment (Figure 1). A spline function can be interpolated from the sGE model over the total gastric emptying 106 time $\left(T_{G E}\right)$ to calculate instantaneous emptying rates entering the SI (Equation 5). 


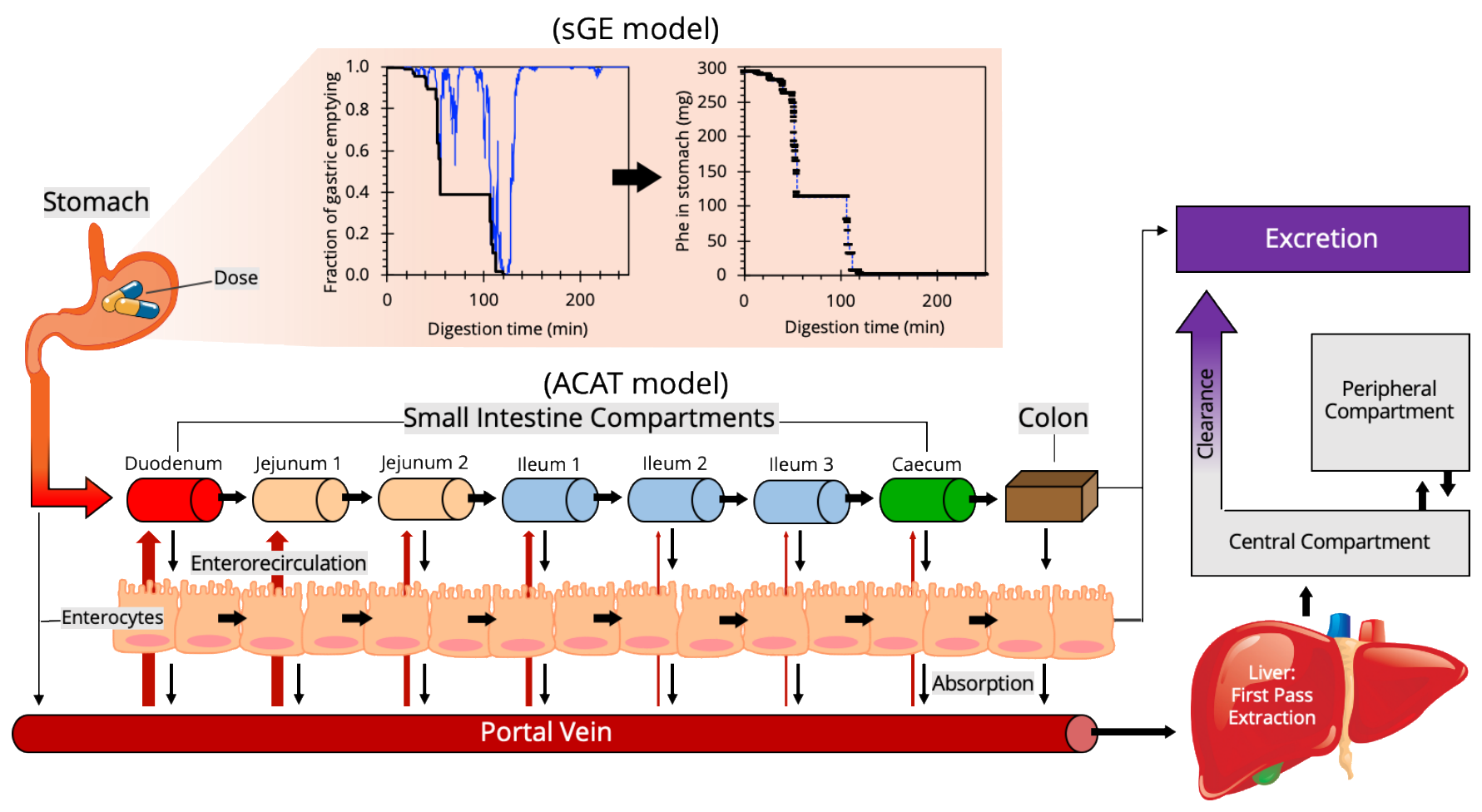

Figure 1. Schematic of the ALT-CAT model for drug absorption.

As in the ACAT model, the stomach empties into a seven compartment SI. Mass transfer differential equations surround the fate of a drug in each compartment, which ultimately defines drug bioavailability. The ALT-CAT model adapts this framework by incorporating the stochastic gastric emptying (sGE) model (orange) of the stomach and, in the case of PKU, models phe absorption as detrimental and phe degradation as therapeutic, with enterorecirculation (red arrows) contributing to luminal phe. Adapted from Agoram et al. (2001) and Macheras et al. $(2003)(15,29)$.

Within each compartment of the ACAT model, the instantaneous concentration of a drug transiting the gut (30) is solubility. While certain physiochemical or formulation properties are simplified with phe, the ALT-CAT model requires the additional mass transport of phe from the blood back into the gut lumen, a phenomenon known as amino acid enterorecirculation or exsorption. This likely occurs from both epithelial polarity (21) - active and passive

121 transport variation between the apical $(A P)$ and basolateral $(B L)$ membranes of the endothelium - and pancreatic 122 and glandular secretions during digestion (30). Transport of phe across a Caco-2 monolayer has been previously 123 modeled as a combination of saturable and non-saturable uptake $(u)$ and efflux $(e)$ in both directions (Equation 6- 
125 flux $\left(J_{\max }\right)\left(\mathrm{mmol} \mathrm{mg}^{-1} \mathrm{~min}^{-1}\right)$ and half maximum concentration $\left(K_{M}\right)(\mathrm{mM})$ values, while first-order kinetics are

126 described by phe-specific flux constants $(f)$. Predicted plasma $(p)$, intracellular $(i)$, and luminal $(l)$ phe concentrations

127 can then inform the model, and enterorecirculation is represented as a net flux $\left(J_{\text {net }}\right)$ ratio and incorporated in the

$128 \mathrm{n}^{\text {th }}$ compartment absorption scale factor $\left(\beta_{n}\right)$.

$$
\begin{gathered}
J_{\text {net }}^{A P P}=\left\langle\frac{J_{\text {max }}^{u, A P} C_{l}}{K_{M}^{u, A P}+C_{l}}+f^{u, A P} C_{l}\right\rangle-\left\langle f^{e, A P} C_{i}\right\rangle \\
J_{\text {net }}^{B L}=\left\langle f^{e, B L} C_{i}\right\rangle-\left\langle\frac{J_{m a x}^{u, B L} C_{p}}{K_{M}^{u, B L}+C_{p}}+f^{u, B L} C_{p}\right\rangle \\
\beta_{n}=\frac{J_{\text {net, }, n}^{B L}}{J_{\text {net }, n}^{A P}}
\end{gathered}
$$

Equation 6

Equation 7

Equation 8

129 To complete the ALT-CAT model, phe degradation can be reframed as therapeutic conversion by PAL. The GIT is 130 populated with more than 1000 species of microorganisms in a community known as the human microbiota. This 131 diverse population is thought to have evolved with the mammalian gut with spatial organization and niche 132 regioselectivity determined by inextricably complex community interactions and ecological synergy. While much of 133 the human microbiota reside in the large intestine, a low but longitudinally increasing microbial population can 134 survive and reside in the SI. The boundaries for microbial biomass present in the duodenum, jejunum, and ileum 135 have been reported (33), with lactic acid bacteria, a group in which the majority of probiotics are classified, 136 encompassing approximately $0.1-10 \%$ of the population (34). Using these regional population metrics, the SI can 137 be randomly populated with a living therapeutic population $\left(M_{L T, n}\right)$ that defines $\mathrm{n}^{\text {th }}$ compartment PAL delivery (Figure 138 2). Furthermore, phe conversion (i.e. PAL expression and activity) can be approximated across the population, with 139 Michaelis-Menten enzyme kinetics $\left(J_{\max }\right.$ and $\left.K_{M}\right)$ defining both phe transport (Equation 9) and PAL activity (Equation 140 10). These adjustments form the ALT-CAT model (Equation 11), using changes in blood plasma phe concentration 141 (Equation 12) as a metric for therapeutic efficacy.

$$
J_{t r}=\frac{V_{m a x}^{t r} C_{l}}{K_{M}^{t r}+C_{l}}
$$


bioRxiv preprint doi: https://doi.org/10.1101/2020.04.01.020677; this version posted April 4, 2020. The copyright holder for this preprint (which was not certified by peer review) is the author/funder, who has granted bioRxiv a license to display the preprint in perpetuity. It is made available under aCC-BY-NC-ND 4.0 International license.

$$
\begin{gathered}
J_{c}=f\left(J_{t r}\right)\left\{\begin{array}{cc}
J_{t r}>J_{c, \text { max }} & \frac{k_{c a t} C_{l}}{M_{L T}} \\
J_{t r} \leq J_{c, \text { max }} & \frac{V_{m a x}^{P A L} C_{i, L T}}{K_{M}^{P A L}+C_{i, L T}}
\end{array}\right\} \\
\frac{d M_{n}}{d t}=k_{t} M_{n-1}-\beta_{n} k_{a} M_{n}-k_{c} M_{n}, \quad n=1,2, \ldots, 7 \\
\frac{d C_{p}}{d t}=\frac{k_{a}}{V} \sum_{n=1}^{7} \beta_{n} M_{n}
\end{gathered}
$$

a.

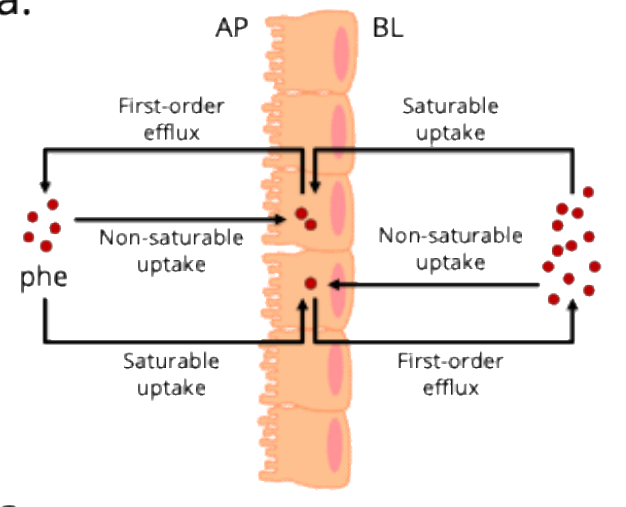

C.

Figure 2. Populating the small intestines with living therapeutics

b.

(a.) In PKU, enterorecirculation of phe back into the lumen contributes to (b.) the mass transfer equations driving phe degradation (therapeutic conversion) by PAL present in each compartment's living therapeutic population. (c.) Each section of the SI has a defined microbial population range. Cross-sections, similar to column plate counts in chromatography, can be generated based on gut length, each with a bounded random microbial population. The full SI can then be equally sectioned into seven compartments as in the ACAT model. Enterorecirculation adapted from Hu and Borchardt (1992) (30). 
bioRxiv preprint doi: https://doi.org/10.1101/2020.04.01.020677; this version posted April 4, 2020. The copyright holder for this preprint (which was not certified by peer review) is the author/funder, who has granted bioRxiv a license to display the preprint in perpetuity. It is made available under aCC-BY-NC-ND 4.0 International license.

\section{Results \& Discussion}

153 Solutions to the differential equations of the ALT-CAT model can be visualized as the change in the phe in each 154 compartment as compared to the start-of-day plasma phe. An example average adult PKU patient, eating four meals

a.

b.

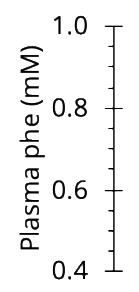
5:00 AM $=$

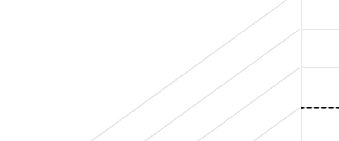<smiles>C1CCCCC1</smiles>
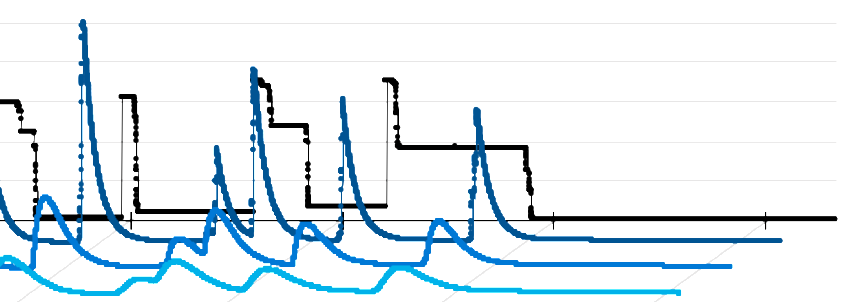

Figure 3. Representative solution to phe digestion in an adult using the ALT-CAT model.

(a.) The sGE model generates a release schedule of phe for 4 meals (average adult) over the course of $24 \mathrm{~h}$. Differential equations quantify instantaneous phe in each compartment, visualized as the relative change (percent difference) in phe compared to a start-of-day plasma phe of $0.5 \mathrm{mM}$. (b.) Blood plasma phe varies by phe absorption and exsorption while a population of living therapeutic converts phe in the lumen of the seven SI compartments. (c.) Urine excretion of $t C A$, or an equivalent biomarker such as hippurate, is proportional to PAL specific activity. 
168 Several physiological parameters of the ALT-CAT model can drastically change across a population, and thus inform, 169 the efficacy of a living therapeutic (Table 1). Drug absorption is proportional to the $P_{\text {eff, }}$ which typically defines the 170 bioavailability of large complex drugs with poor solubility. In the case of PKU, phe is an essential amino acid that is 171 readily absorbed without much resistance, observed as sequentially less phe present in compartments of the ALT172 CAT model (Figure 3). Physiological properties that change between age and sex groups, such as the SI length and 173 diameter, dictate the available surface area for absorption, with villi and microvilli amplifying the cylindrical surface 174 area by 60-120 times (35). Additionally, when considering a metabolic disorder such as PKU, body size, amount of 175 protein per meal, number of meals per day, frequency of feeding, and sleep schedules can all drastically impact the 176 availability, and thus metabolism and therapeutic degradation of phe.

We ran nine age groups through the ALT-CAT model, chosen based on physiological properties of the stomach and SI. Starting with a medium-high blood plasma phe concentration $(0.5 \mathrm{mM})$ and $1 \%$ living therapeutic population, the end-of-day concentration for 1000 simulations were observed to be influenced by these physiological factors (Figure 4). Each simulation is randomly built using a normal distribution of gut length, body weight, meal phe content, surface area multiplier, and microbial population (Table 1). For the infant and toddler groups, there was much more variability in outcomes. Notably, an all-liquid diet at this age is better modelled as a linear gastric emptying process, which, alongside a large number of meals and short intestine lengths, leave little time for therapeutic conversion of phe. With the majority of phe being freely absorbed, the likely significant contributor to the final distributions is the surface area multiplier $\left(\beta_{S A}\right)$. Perhaps an adjuvant strategy involving phe transport 187 inhibitors would be impactful for these age groups. Large neutral amino acid (LNAA) supplementation has been 188 effective in PKU adults (36), though with the importance of amino acid concentrations for neural development, not currently recommended for children. Inhibition of epithelial LNAA transporters, such as T-type amino acid transporter (TAT1), with D-isomers or phe derivatives could more specifically target intestinal absorption $(37,38)$. 
191 The ALT-CAT model reiterates reported evidence that gastric emptying is rate-limiting, and once the sGE model is

192 implemented with 7- to 12-month-olds, slower phe introduction corresponds to better therapeutic conversion (i.e.

193 lower plasma phe concentration). Older age groups have designated hours of long sleep as well, allowing phe to be

194 degraded without a meal dictating concentrations. Larger GITs obviously provide more space for more microbes as

195 a percent of the population.

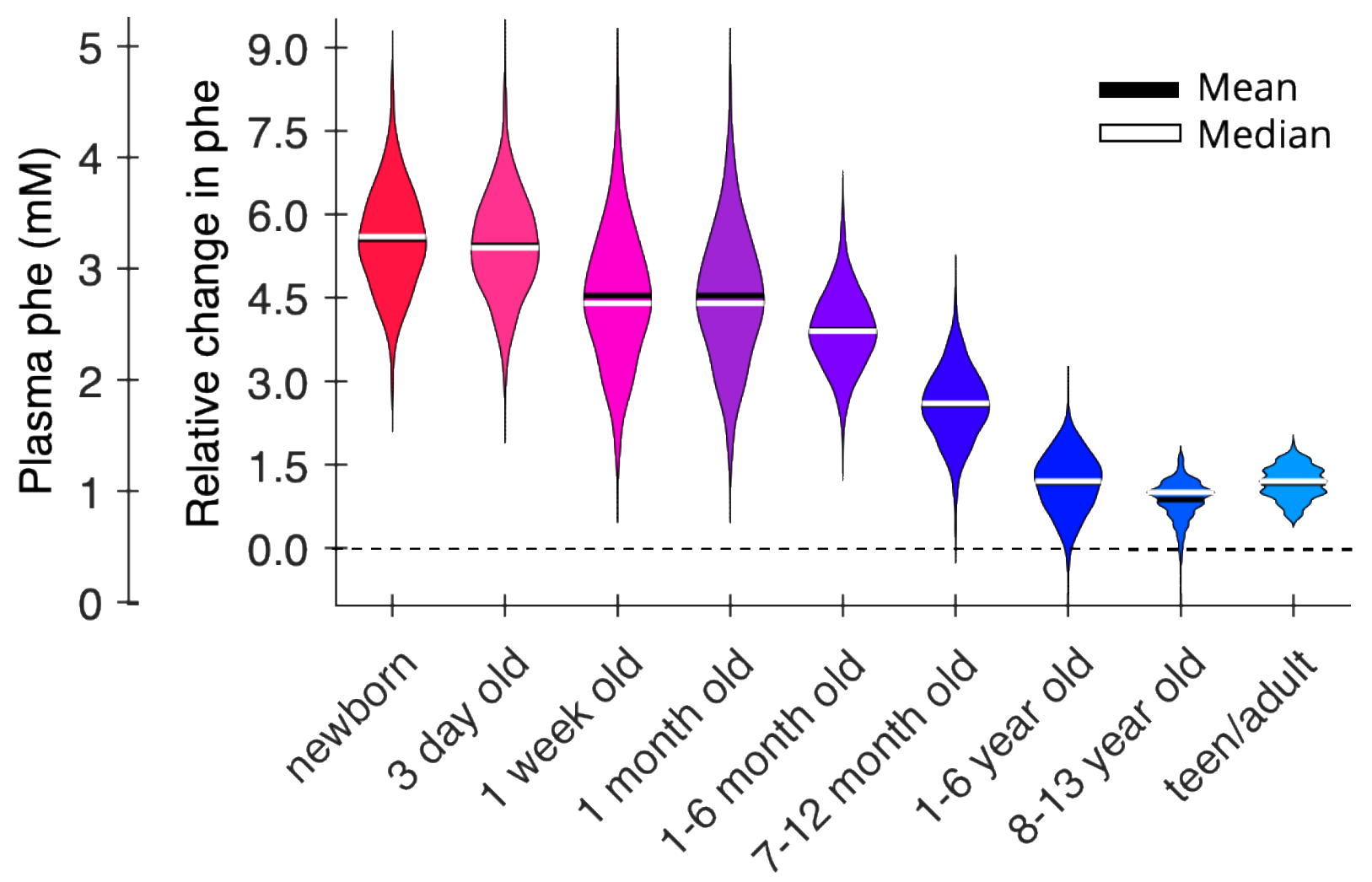

Figure 4. Changes in therapeutic efficacy across different age groups as measured by end-of-day blood phe concentration. Running 1000 simulations of the ALT-CAT model across age groups in which GI physiological properties and meal sizes and feeding schedules vary. The GIT is populated by designating $1 \%$ of the bacteria as the living therapeutic and results are

Unfortunately, the physiology of the gut does not lend to metabolic intervention easily, and each age group had plasma phe ubiquitously increase to unsafe levels (Figure 4). As a countering tactical measure, drug formulations for 
mucoadhesion and increase residence time or cell population (16), bacterial chassis selection to target regional

207 success $(40,41)$, and enzyme choice and expression to increase specific activity per cell $(40,41)$. Effectively, the 208 agenda in each case is to increase the level of therapeutic intervention at earlier stages of digestion. This can be 209 simulated in the ALT-CAT model using a coverage multiplier ( $\left.\alpha_{C}\right)$ (Equation 13). This is created as the mean of a log210 normal distribution to define the living therapeutic population. While it is represented as bacterial concentration in 211 the model, this is a representative parameter of "active therapeutic agent per unit volume of $\mathrm{SI}^{\text {" in each }}$ 212 compartment, influenced by gastric survival $(G)$, availability $(A)$, regioselective niches $(R)$, surface area $(S A)$, transit 213 time $\left(T_{S I}\right)$, and total microbial population $\left(M_{t o t}\right)$ (Figure 5a). By increasing the $\alpha_{C_{1}}$ the blood plasma phe concentration 214 is noticeably impacted in both children and adults. In the 1- to 6-month-old age group, ALT-CAT model solutions 215 with $\alpha_{C}=1$, which designates a mean $2.5 \%$ of the bacterial population as active, begin to lower plasma phe (Figure 216 5b). While this is a significant fraction of gut bacteria being replaced with the therapeutic, it corresponds to $10^{10}$ $21710^{11}$ cells, within a reasonable order-of-magnitude for a dosing regimen. As the length of the SI and overall bacterial 218 population is much larger in adults, a lower percent $\left(\alpha_{C}=0 ;\right.$ mean $\left.=0.8 \%\right)$ is impactful. These comparisons can offer 219 insight into dosing regimen depending on physiology, diet, and bacterial chasses.

$$
\begin{aligned}
& G(t)=(\text { Dose })(\text { gastric survival }) \\
& A(G, t)=\left(G_{i}\right)(\text { dose release schedule }) \\
& R(A, t, x)=\left(A_{i}\right)(\text { regioselective survival })
\end{aligned}
$$

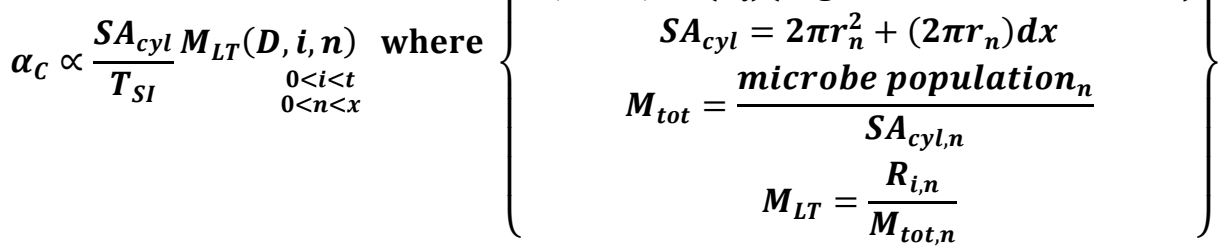

$$
\begin{aligned}
& \alpha_{E} \propto\left(J_{c}\right)\left(M_{L T}\right)(E) \\
& \alpha_{T} \propto\left(\left(\beta_{S A} S A_{c y l}\right)\left(\beta_{n}\right)\left(F_{a}\right)\right)^{-1}
\end{aligned}
$$

Equation 13

Equation 14

Equation 15 
a.

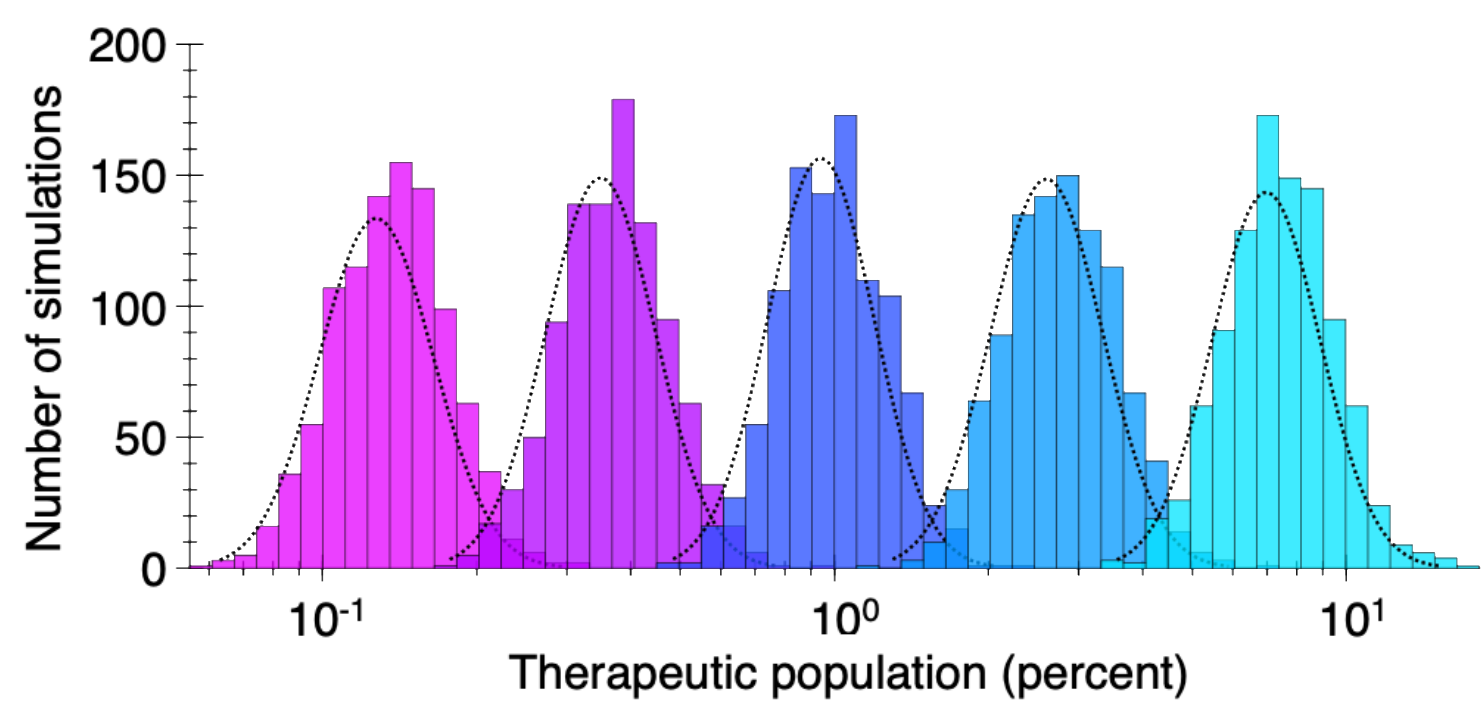

coverage multiplier

b.

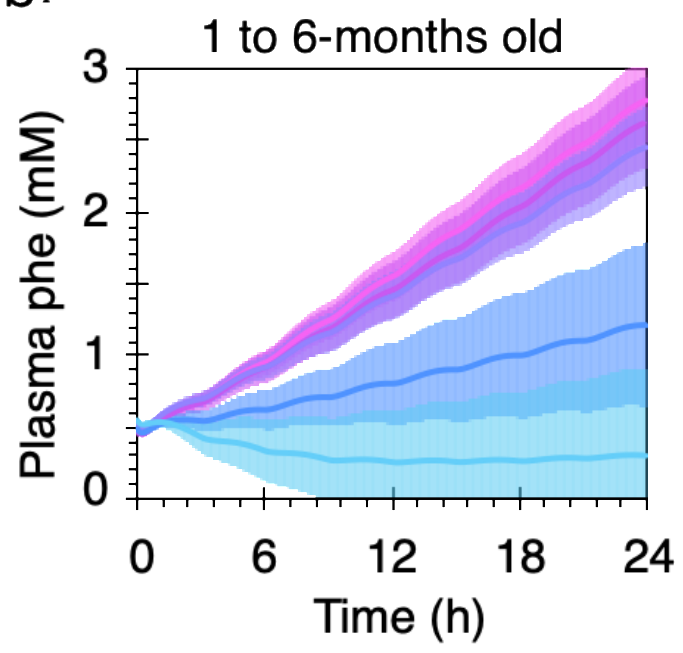

C.

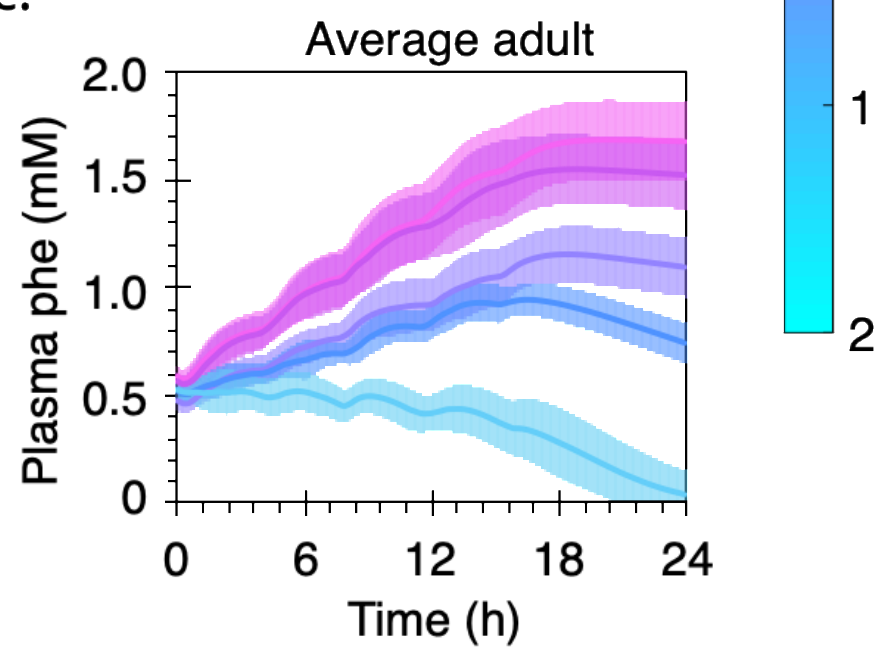

Figure 5. Therapeutic factor impacts on ALT-CAT solutions

A PAL-based living therapeutic to treat PKU is highly impacted by the number of bacteria able to degrade phe. (a.) The mean of a lognormal distribution is used to randomly populate the gut within a population range and is represented in the ALT-CAT model as the coverage multiplier $\left(\alpha_{C}\right)$. Varying $\alpha_{C}$ in the GIT of (b.) 1 to 6-month old babies and (c.) average adults, represented as the blood plasma phe concentration over a $24 \mathrm{~h}$ period as mean (line) and standard deviation (shaded region) of 1000 solutions.

As a thought experiment, it is more realistic to control enzyme properties within a bacterial cell than it is to control the many complex environmental interactions bacteria may encounter in the SI. Enzymatic specific activity, whether 
232 that be from increased $M_{L T}$ or higher protein expression $(E)$ or turnover $\left(k_{\text {cat }}\right)$, can be more informative as a metric in

233 the ALT-CAT model solution space. Thus, similar simulations with each age group were performed using an enzyme

234 multiplier $\left(\alpha_{E}\right)$ (Equation 14) applied to PAL rather than microbial population $\left(\alpha_{C}\right)$. Initially, moving from $\alpha_{C}=0$

$235(\sim 0.8 \%$ cells $)$ to $\alpha_{C}=1(\sim 2.5 \%$ cells $)$ yielded a bacterial population that was efficacious in 1 - to 6 -month-old babies;

236 this is 3.125-fold change. Reframing this, keeping the bacterial population constant but increasing specific enzyme

237 activity by 3.125 -fold (i.e. $\alpha_{E}=3.125$ ) has an equivalent impact on lowering the end-of-day plasma phe (Figure $\left.6 a\right)$.

238 That is, enzyme specific activity is proportional to $M_{L T}$. 

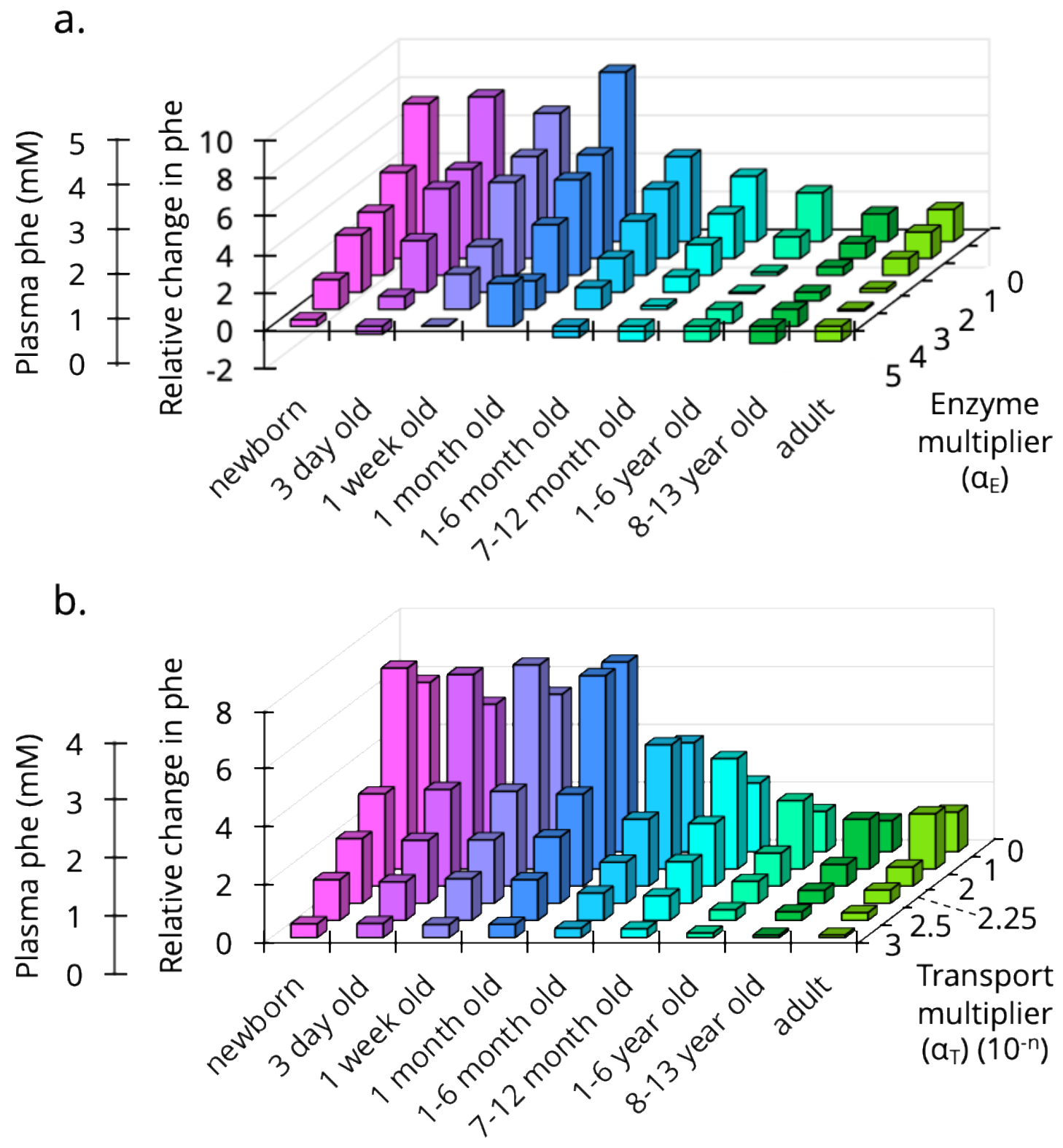

Figure 6. Exploring the solution space of the ALT-CAT model.

While keeping the coverage multiplier constant $\left(\alpha_{C}=0 ; \sim 0.8 \%\right.$ ), the end-of-day plasma phe concentration was calculated for (a.) increasing PAL specific activity by changing the enzyme multiplier $\left(\alpha_{E}\right)$, and $(b$.) slowing the absorption of phe by increasing the permeability multiplier $\left(\alpha_{T}\right)$. Each bar is the mean of 100 simulations.

Alternatively, transport of phe across the epithelium is fast, approximately $4.1 \times 10^{-4} \mathrm{~cm} / \mathrm{s}(42)$, and on the high end of typical drugs $(42,43)$. Slowing $P_{\text {eff }}$ or reducing $\beta_{S A}$ or enterorecirculation $\left(\beta_{n}\right)$ using a transport multiplier $\left(\alpha_{T}\right)$ can 
absorption) from a living therapeutic (Figure $6 \mathrm{~b}$ ). Lowering the $P_{\text {eff }}$ of phe by 225 -fold $\left(\alpha_{T}=2.25\right)$, improves the treatment 2.3-fold for 1 - to 6-month-old babies (Figure 6b). This level of change unlikely to be feasible for the treatment of PKU using LNAA supplementation. However, generalizing beyond phe and treating PKU, this new $P_{\text {eff }}$ $\sim 10^{-4}$ to $10^{-5} \mathrm{~cm} / \mathrm{s}$ (i.e. $\alpha_{T}=2.25$ ) falls within the range of typical small molecule drugs $(42,43)$. So, considering these trends conceptually as the production of a typical drug with a living therapeutic, if the drug has poor bioavailability $254\left(\alpha_{T}=0\right)$, the current-best-reported production $\left(\alpha_{E}=1\right)$ would require $\sim 2.5 \%$ population coverage $\left(\alpha_{C}=1\right)$. However, 255 improving drug bioavailability by increasing permeability $\left(\alpha_{T}=2.25\right)$ now only requires $\sim 1 \%$ (or $\left.2.5 \div 2.3\right)$ of the bacterial population to produce the same efficacy, or approximately $\alpha_{C}=0$. Slower absorption requires a lower dose. These model adjustments provide examples as to how tuning different parameters can inform design benchmarks when constructing living therapeutics for different applications.

These three parameters (bacterial population, enzyme activity, and transport) represent avenues of engineering. As 261 such, a combinatorial approach to dial in system- or therapy-specific parameters can be informed by running the 262 ALT-CAT model to set investigative benchmarks and clinical boundaries. Additional drug physiochemical and 263 formulation properties and Gl physiological properties can easily be added and assessed using multipliers as 264 explored in Figure 6. While PKU and a PAL-based EST offer a well-suited case study for the development and 265 evaluation of the ALT-CAT model, we present this as a generalized tool for oral drug development and the 266 advancement of living therapeutics as a platform.

\section{Supplemental Information}

269 The MATLAB files for model can be found at the Nair lab GitHub page: https://github.com/nair-lab/ALT-CAT 
273 of Health.

275 Conflict of Interest

276 None.

\section{References}

279

280

281

282

283

284

285

286

287

288

289

290

291

292

293

294

295

296

297

298

299

300

301

302

303

304

305

306

307

308

1. Amidon GL, Lennernäs H, Shah VP, Crison JR. 1995. A Theoretical Basis for a Biopharmaceutic Drug Classification: The Correlation of in Vitro Drug Product Dissolution and in Vivo Bioavailability. Pharmaceutical Research: An Official Journal of the American Association of Pharmaceutical Scientists 12:413-420.

2. Lipinski CA, Lombardo F, Dominy BW, Feeney PJ. 2012. Experimental and computational approaches to estimate solubility and permeability in drug discovery and development settings. Advanced Drug Delivery Reviews 64:417.

3. Turco L, Catone T, Caloni F, Consiglio E di, Testai E, Stammati A. 2011. Caco-2/TC7 cell line characterization for intestinal absorption: How reliable is this in vitro model for the prediction of the oral dose fraction absorbed in human? Toxicology in Vitro 25:13-20.

4. Lennernäs H, Ahrenstedt Ö, Hällgren R, Knutson L, Ryde M, Paalzow LK. 1992. Regional Jejunal Perfusion, a New in Vivo Approach to Study Oral Drug Absorption in Man. Pharmaceutical Research: An Official Journal of the American Association of Pharmaceutical Scientists.

5. Antunes F, Andrade F, Araújo F, Ferreira D, Sarmento B. 2013. Establishment of a triple co-culture in vitro cell models to study intestinal absorption of peptide drugs. European Journal of Pharmaceutics and Biopharmaceutics 83:427-435.

6. Bein A, Shin W, Jalili-firoozinezhad S, Park MH, Kim HJ, Ingber DE. 2018. Microfluidic Organ-on-a-Chip Models of Human Intestine. Cellular and Molecular Gastroenterology and Hepatology 5:659-668.

7. Minekus M, Smeets-Peeters M, Havenaar R, Bernalier A, Fonty G, Marol-Bonnin S, Alric M, Marteau P, Huis In't Veld JHJ. 1999. A computer-controlled system to simulate conditions of the large intestine with peristaltic mixing, water absorption and absorption of fermentation products. Applied Microbiology and Biotechnology 53:108-114.

8. Basant N, Gupta S, Singh KP. 2016. Predicting human intestinal absorption of diverse chemicals using ensemble learning based QSAR modeling approaches. Computational Biology and Chemistry 61:178-196.

9. Yu LX, Amidon GL. 1999. A compartmental absorption and transit model for estimating oral drug absorption. International Journal of Pharmaceutics 186:119-125.

10. di Meo F, Fabre G, Berka K, Ossman T, Chantemargue B, Paloncýová M, Marquet P, Otyepka M, Trouillas P. 2016. In silico pharmacology: Drug membrane partitioning and crossing. Pharmacological Research 111:471486.

11. Rowland M, Peck C, Tucker G. 2011. Physiologically-Based Pharmacokinetics in Drug Development and Regulatory Science. Annual Review of Pharmacology and Toxicology 51:45-73. 
12. Willmann S, Thelen K, Lippert J. 2012. Integration of dissolution into physiologically-based pharmacokinetic models III: PK-Sim. Journal of Pharmacy and Pharmacology 64:997-1007.

13. Marsousi N, Desmeules JA, Rudaz S, Daali Y. 2018. Prediction of drug-drug interactions using physiologicallybased pharmacokinetic models of CYP450 modulators included in Simcyp software. Biopharmaceutics and Drug Disposition 39:3-17.

14. Gobeau N, Stringer R, de Buck S, Tuntland T, Faller B. 2016. Evaluation of the GastroPlus ${ }^{\mathrm{TM}}$ Advanced Compartmental and Transit (ACAT) Model in Early Discovery. Pharmaceutical Research 33:2126-2139.

15. Agoram B, Woltosz WS, Bolger MB. 2001. Predicting the impact of physiological and biochemical processes on oral drug bioavailability. Advanced Drug Delivery Reviews 50:\$41-\$67.

16. Mays ZJ, Nair NU. 2018. Synthetic biology in probiotic lactic acid bacteria: At the frontier of living therapeutics. Curr Op Biotechnol 53:224-231.

17. Bober JR, Beisel CL, Nair NU. 2018. Synthetic Biology Approaches to Engineer Probiotics and Members of the Human Microbiota for Biomedical Applications 277-300.

18. Waller MC, Bober JR, Nair NU, Beisel CL. 2017. Toward a genetic tool development pipeline for host-associated bacteria. Curr Opin Microbiol 38:156-164.

19. Mimee M, Citorik RJ, Lu TK. 2016. Microbiome therapeutics - Advances and challenges. Advanced Drug Delivery Reviews 105:44-54.

20. Isabella VM, Ha BN, Castillo MJ, Lubkowicz DJ, Rowe SE, Millet YA, Anderson CL, Li N, Fisher AB, West KA, Reeder PJ, Momin MM, Bergeron CG, Guilmain SE, Miller PF, Kurtz CB, Falb D. 2018. Development of a synthetic live bacterial therapeutic for the human metabolic disease phenylketonuria. Nat Biotechnol 36:857-867.

21. Chang S, Ming T, Bourget L, Lister C. 1995. A new theory of enterorecirculation of amino acids and its use for depleting unwanted amino acids using oral enzyme-artificial cells, as in removing phenylalanine in phenylketonuria. Artificial Cells, Blood Substitutes, and Biotechnology 23:1-21.

22. West KA, Perreault M, Kurtz CB, Wagner DA, Charbonneau MR, Dagon Y, Degar AJ, Kotula JW, Millet YA, Brennan AM, Miller PF, Puurunen MK, Denney WS, Isabella VM, Antipov E. 2019. An engineered E. coli Nissle improves hyperammonemia and survival in mice and shows dose-dependent exposure in healthy humans. Sci Transl Med 11:eaau7975.

23. Rhimi M, Bermudez-Humaran LG, Huang Y, Boudebbouze S, Gaci N, Garnier A, Gratadoux JJ, Mkaouar H, Langella P, Maguin E. 2015. The secreted I-arabinose isomerase displays anti-hyperglycemic effects in mice. Microbial Cell Factories 14:204.

24. Lin Y, Krogh-Andersen K, Hammarström L, Marcotte H. 2017. Lactobacillus delivery of bioactive interleukin-22. Microbial Cell Factories 16:148.

25. Zhang B, Li A, Zuo F, Yu R, Zeng Z, Ma H, Chen S. 2016. Recombinant Lactococcus lactis NZ9000 secretes a bioactive kisspeptin that inhibits proliferation and migration of human colon carcinoma HT-29 cells. Microbial Cell Factories 15:102.

26. Yu LX, Crison JR, Amidon GL. 1996. Compartmental transit and dispersion model analysis of small intestinal transit flow in humans. Int J Pharm 140:111-118.

27. Yokrattanasak J, de Gaetano A, Panunzi S, Satiracoo P, Lawton WM, Lenbury Y. 2016. A simple, realistic stochastic model of gastric emptying. PLoS ONE 11:1-15.

28. Locatelli I, Mrhar A, Bogataj M. 2009. Gastric emptying of pellets under fasting conditions: A mathematical model. Pharmaceutical Research 26:1607-1617.

29. Macheras P, Karalis V, Valsami G. 2013. Keeping a critical eye on the science and the regulation of oral drug absorption: A review. Journal of Pharmaceutical Sciences 102:3018-3036.

30. Hu M, Borchardt RT. 1992. Transport of a large neutral amino acid in a human intestinal epithelial cell line (Caco-2): uptake and efflux of phenylalanine. BBA - Molecular Cell Research 1135:233-244. 
31. Hidalgo IJ, Borchardt RT. 1990. Transport of a large neutral amino acid (phenylalanine) in a human intestinal epithelial cell line: Caco-2. BBA - Biomembranes 1028:25-30.

32. Walter J, Ley R. 2011. The Human Gut Microbiome: Ecology and Recent Evolutionary Changes. Annu Rev Microbiol 65:411-429.

33. Douillard FP, de Vos WM. 2014. Functional genomics of lactic acid bacteria: From food to health. Microb Cell Fact 13:S8.

34. Helander HF, Fändriks L. 2014. Surface area of the digestive tract-revisited. Scandinavian Journal of Gastroenterology 49:681-689.

35. Zhang Y, Jia X, Wang L, Liu J, Ma G. 2011. Preparation of Ca-alginate microparticles and its application for phenylketonuria oral therapy. Industrial and Engineering Chemistry Research 50:4106-4112.

36. Matalon R, Michals-Matalon K, Bhatia G, Burlina AB, Burlina AP, Braga C, Fiori L, Giovannini M, Grechanina E, Novikov P, Grady J, Tyring SK, Guttler F. 2007. Double blind placebo control trial of large neutral amino acids in treatment of PKU: Effect on blood phenylalanine. Journal of Inherited Metabolic Disease 30:153-158.

37. Mariotta L, Ramadan T, Singer D, Guetg A, Herzog B, Stoeger C, Palacín M, Lahoutte T, Camargo SMR, Verrey F. 2012. T-type amino acid transporter TAT1 (SIc16a10) is essential for extracellular aromatic amino acid homeostasis control. Journal of Physiology 590:6413-6424.

38. Kim DK, Kanai Y, Chairoungdua A, Matsuo H, Cha SH, Endou H. 2001. Expression Cloning of a Na+-independent Aromatic Amino Acid Transporter with Structural Similarity to $\mathrm{H}+/$ Monocarboxylate Transporters. Journal of Biological Chemistry 276:17221-17228.

39. Mays ZJS, Chappell TC, Nair NU. 2020. Quantifying and Engineering Mucus Adhesion of Probiotics. ACS Synthetic Biology acssynbio.9b00356.

40. Jendresen CB, Stahlhut SG, Li M, Gaspar P, Siedler S, Förster J, Maury J, Borodina I, Nielsen AT. 2015. Highly active and specific tyrosine ammonia-lyases from diverse origins enable enhanced production of aromatic compounds in bacteria and Saccharomyces cerevisiae. Applied and Environmental Microbiology 81:4458-4476.

41. Wu B, Szymański W, Heberling MM, Feringa BL, Janssen DB. 2011. Aminomutases: Mechanistic diversity, biotechnological applications and future perspectives. Trends in Biotechnology 29:352-362.

42. Dahlgren D, Roos C, Sjögren E, Lennernäs H. 2015. Direct in Vivo Human Intestinal Permeability (Peff) Determined with Different Clinical Perfusion and Intubation Methods. Journal of Pharmaceutical Sciences 104:2702-2726.

43. Wolk O, Markovic M, Porat D, Fine-Shamir N, Zur M, Beig A, Dahan A. 2019. Segmental-Dependent Intestinal Drug Permeability: Development and Model Validation of In Silico Predictions Guided by In Vivo Permeability Values. Journal of Pharmaceutical Sciences 108:316-325. 
387 Table 1. Parameters entered into the ALT-CAT model

\begin{tabular}{|c|c|c|c|}
\hline \multicolumn{3}{|c|}{ Model parameter } & \multirow{2}{*}{$\begin{array}{l}\text { Value } \\
0.045\end{array}$} \\
\hline excretion rate, $k_{\text {excr }}$ & $\left(\min ^{-1}\right)$ & & \\
\hline blood volume to weight ratio & $\left(\mathrm{L} \mathrm{kg}^{-1}\right)$ & & 0.075 \\
\hline enzyme to cell weight ratio & $\left(\mathrm{mg} \mathrm{mg}^{-1}\right)$ & & 0.165 \\
\hline effective permeability coefficient, $P_{\text {eff }}$ & $\left(\mathrm{cm} \mathrm{min} \mathrm{m}^{-1}\right)$ & & 0.03 \\
\hline surface area multiplier, $\beta_{S A}$ & & & 60 to 120 \\
\hline maximum rate apical uptake, $J_{\max }^{u, A P}$ & $\left(\mathrm{nmol} \mathrm{min} \mathrm{mg}^{-1} \mathrm{mg}^{-1}\right)$ & & 16.1 \\
\hline phe at half max apical uptake, $K_{M}^{u, A P}$ & $(\mathrm{mM})$ & & 2.7 \\
\hline apical uptake rate constant, $f^{\mu, A P}$ & $\left(\mathrm{nmol} \mathrm{min} \mathrm{m}^{-1} \mathrm{mg}^{-1} \mathrm{mM}^{-1}\right)$ & & 0.2 \\
\hline \multirow[t]{2}{*}{ apical efflux rate constant, $f^{f, A P}$} & $\left(\mathrm{nmol} \mathrm{min} \mathrm{m}^{-1} \mathrm{mg}^{-1} \mathrm{mM}^{-1}\right)$ & & 0.289 \\
\hline & & Duodenum & $10^{3}$ to $10^{4}$ \\
\hline \multirow[t]{2}{*}{ microbe population boundaries } & (cells $\mathrm{mL}^{-1}$ ) & Jejunum & $10^{4}$ to $10^{6}$ \\
\hline & & Ileum & $10^{6}$ to $10^{9}$ \\
\hline
\end{tabular}

\begin{tabular}{|c|c|c|}
\hline \multicolumn{2}{|l|}{ Model parameter } & Value \\
\hline PAL specific activity, Jenz & & 3.5 \\
\hline maximum internal to luminal phe, $J_{\max }^{c i}$ & $(\mathrm{mM})$ & 13.26 \\
\hline phe at half max internal to luminal phe, $K_{M}^{c i}$ & $(\mathrm{mM})$ & 4.203 \\
\hline maximum rate $E$. coli phe transport, $J_{\max }^{t r}$ & $\left(\mathrm{mmol} 30 \mathrm{~s}^{-1} \mathrm{mg}^{-1}\right)$ & 0.75 \\
\hline phe at half max E.coli transport, $K_{M}^{t r}$ & $(\mathrm{mM})$ & 0.00072 \\
\hline maximum rate basolateral uptake, $J_{\max }^{u, B L}$ & $\left(\mathrm{nmol} \mathrm{min} \mathrm{mg}^{-1} \mathrm{mg}^{-1}\right)$ & 1.07 \\
\hline phe at half max basolateral uptake, $K_{M}^{u, B L}$ & $(\mathrm{mM})$ & 0.18 \\
\hline basolateral uptake rate constant, $f^{u, B L}$ & nol $\mathrm{min}^{-1} \mathrm{mg}^{-1} \mathrm{mM}^{-1}$ ) & 0.2 \\
\hline basolateral efflux rate constant, $f^{e, B L}$ & nol $\mathrm{min}^{-1} \mathrm{mg}^{-1} \mathrm{mM}^{-1}$ ) & 0.476 \\
\hline sGE model alpha, $\alpha$ & & $1.00 \mathrm{E}-06$ \\
\hline
\end{tabular}

6

sGE model beta, $\beta$

\begin{tabular}{|c|c|c|c|c|c|c|c|c|c|c|}
\hline \multicolumn{2}{|l|}{ Model parameter } & newborn & $\begin{array}{c}3- \\
\text { day-old }\end{array}$ & $\begin{array}{c}1- \\
\text { week-old }\end{array}$ & $\begin{array}{c}1- \\
\text { month-old }\end{array}$ & $\begin{array}{c}\text { Value } \\
\text { 1- to 6- } \\
\text { month-old }\end{array}$ & $\begin{array}{l}\text { 7- to } 12- \\
\text { month-old }\end{array}$ & $\begin{array}{c}1 \text { - to } 6- \\
\text { year-old }\end{array}$ & $\begin{array}{l}\text { 8- to } 13- \\
\text { year-old }\end{array}$ & adult \\
\hline SI length & $(\mathrm{cm})$ & $246.5 \pm 56.2$ & $246.5 \pm 56.2$ & $246.5 \pm 56.2$ & $246.5 \pm 56.2$ & $351.4 \pm 97.8$ & $359.5 \pm 75.7$ & $423.0 \pm 99.0$ & $464.2 \pm 103.1$ & $595.5 \pm 101.8$ \\
\hline SI internal diameter & $(\mathrm{cm})$ & 1.5 & 1.5 & 1.5 & 1.5 & 1.5 & 1.5 & 2.0 & 2.5 & 2.5 \\
\hline weight & $(\mathrm{kg})$ & $3.4 \pm 0.2$ & $3.4 \pm 0.3$ & $3.6 \pm 0.2$ & $4.4 \pm 0.3$ & $6.2 \pm 0.3$ & $7.9 \pm 0.4$ & $17.5 \pm 1.7$ & $35 \pm 5.0$ & $71.0 \pm 5.1$ \\
\hline number of meals & & 12 & 12 & 10 & 8 & 8 & 6 & 5 & 4 & 4 \\
\hline low phe diet & $\left(\mathrm{mg} \mathrm{kg}^{-1} \mathrm{~d}^{-1}\right)$ & $58 \pm 18$ & $58 \pm 18$ & $58 \pm 18$ & $58 \pm 18$ & $40 \pm 10$ & $31 \pm 8.5$ & $20 \pm 1$ & $14 \pm 1$ & $14 \pm 1$ \\
\hline gastric half emptying time, $T_{G E}$ & $(\min )$ & 35 & 35 & 35 & 48 & 60 & 90 & 90 & 90 & 120 \\
\hline SI transit time, $T_{S I}$ & $(\min )$ & 1.5 & 1.5 & 1.5 & 1.5 & 3.5 & 3.5 & 3.5 & 3.5 & 3.5 \\
\hline sleep time & (h) & 0 & 0 & 0 & 0 & 0 & 10 & 11 & 11 & 9 \\
\hline
\end{tabular}

